show the geology of Great Britain. For this purpose the country has been divided into areas or regions that have a definite geological and also geographical identity. Examples are London and Thames Valley, the Weald of Kent, Devon and Cornwall, South Wales, North Wales, Hampshire Basin, Northern Highlands of Scotland, Central Valley of Scotland. Each region is fully illustrated with maps, photographs, sections, rocks, fossils and minerals. A special descriptive handbook of each province is being written by an expert geologist who knows the district thoroughly.

In the second gallery, the exhibits are intended to explain the origin of the prinçipal metals and the economic application of geology. In the table cases are selected specimens of the ores of iron, lead, zinc, copper, manganese, etc., and also a full exposition of useful non-metallic minerals such as talc, gypsum, china clay, rock salt. In special cases there is a large series of British building stones, and such subjects as roadstones, slates, cements, brick clays and asphalts will also have space assigned to them.
One of the most important features of this Museum is the accommodation provided for research material and for investigators who wish to work on the Survey's collections. In the top of the Museum there is a third gallery (not visible from the main floor) with about 16,000 feet of floor space, excellently lighted. This is to be reserved entirely for cabinets containing those specimens of minerals, rocks and fossils that are of special interest and importance, and likely to be consulted by scientific experts. There is also in the basement of the Museum a large store containing drawers filled with material of less importance which requires to be preserved not for its inherent interest but rather as a record on which statements in the Survey memoirs are founded.

The new Museum and Offices are nearly three times as large as the building formerly occupied. The cost of the building was approximately $£ 220,000$. The old Museum in Jermyn Street has been let on a building lease by the Commissioners of Crown Lands at a yearly rental of $£ 11,000$.

\title{
Clinical Science within the University
}

$\mathrm{I}^{\mathrm{N}}$ $\mathrm{N}$ the Huxley Lecture delivered at the University of Birmingham on March 14 and published in the British Medical Journal of March 30, Sir Thomas Lewis made a strong appeal on behalf of the recognition of clinical science, which may be regarded as an answer to the presidential address of Sir Frederick Gowland Hopkins on "Clinical Medicine and Science", a survey of which appeared in NatuRE of December 8, 1934 (p. 867). In his address Sir Frederick expressed his conviction that the scope for really controlled experiments applicable to the human body was limited, and he deprecated the growing tendency to distribute the funds provided for medical research in the endowment of the clinic at the expense of biological science, and particularly biophysics and biochemistry.

Sir Thomas Lewis started by quoting with approval the declaration made by Sir James Paget sixty-five years ago, that "clinical sejence has as good a claim to the name and rights and self-subsistence as any other department of biology" ; but he used the term "clinical science" in a wider sense than Paget, who confined it to researches on living man, by defining it as "the branch of knowledge that centres upon diseased human beings, but which also includes relevant parts of the allied sciences". The field of clinical science therefore should include physiology, morbid anatomy and experimental medicine.
Sir Thomas emphasised the point that clinical science is not identical with clinical medicine and clinical surgery, and drew a distinction between the science and art of medicine ; but he maintains that a university must possess a strong scientific department inspired by direct clinical interests.

As regards experimental work, Sir Thomas declared that every remedy employed to-day is the result of direct experiment on man, as is best exemplified by vaccination, antiseptic surgery and general anæsthesia. Only safe and beneficial experiments are justifiable, and no experiments should be carried out except with the patient's consent. In Sir Thomas's opinion, too many experiments have been and are still being performed; a reduction in their number, and their conduct on a stricter, safer and more productive basis are desirable.

The first requirement of a university department of elinical science is an out-patient department and an in-patient service sufficient to supply ample material for research and teaching, the size of the departments to be decided partly by local conditions and partly by the activities of the professor and his assistants. While admitting that clinical science is essentially a laboratory science, Sir Thomas does not think that the laboratory should be a place reserved for animals. On the contrary, he maintained that laboratories for the 
examination of patients as well as of animals should be close to the clinical services, and even directly attached to the ward or out-patient department.

Although many valuable discoveries may still be anticipated from those actively engaged in the practice of medicine and surgery, Sir Thomas expressed his conviction that in many directions advances may more readily come from men who are able to give their whole time to research, unhampered by routine duties. Appointments for clinical research are therefore required, and no more suitable place for such appointments could be found than within a university, where persons engaged in research would enjoy the stimulus derived from teaching and find a congenial atmosphere.

Sir Thomas then passed on to the subject of the medical education of to-day, in which, as is generally agreed, he holds there are grave defects. The curriculum is overloaded not only by the preliminary sciences, including anatomy, physiology and general pathology, but also on the clinical side.

The plan suggested by Sir Thomas Lewis as a remedy is as follows: There should be a first course consisting of the outlines of human anatomy and physiology, with special stress laid on what is immediately applicable to the study of disease. The second course, which would not be compulsory for all medical students but would be suitable to a science degree or to those who intended to take up physiology, pathology or clinical science as a career, would be one of more advanced physiology. The third or final course would consist partly of general and practical instruction along existing lines, emphasis being laid on all that is essential to general practice. The teaching should be mainly concerned with common diseases and remedies of proved value and ready application. The outlines of clinical science should be included in this course, which would be taken by all medical students, but higher examinations would be held by the Royal Colleges and possibly by the universities, and there might be room for a university degree in clinical science for those who proposed to adopt an academic career.

As to the final stage of the student's preparation for medical practice, Sir Thomas granted that the best teacher is the man in active practice, who not only understands disease and its treatment in detail but is also able to manage sick people and their friends. These accomplishments, however, do not qualify the teacher for the post of university professor in clinical science, whose duties should rather be to deal with the principles and problems of clinical science, and with the patients only to exemplify specific points. The former would include the causes of disease, the principles of hereditary transmission of human diseases, the reaction of man to his environment, physical injuries and chemical poisons, the meaning and effects of infection, the significance of sexual, racial and other predispositions to disease, and the origin of new growths in man.

In conclusion, Sir Thomas repeated that it is largely within the power of the universities to establish clinical science on the same basis as the allied sciences of physiology and pathology, as distinct from the practical art of medicine.

\section{British Chemical Abstracts}

$\triangle$ LMOST exactly eight years ago, the appear$A$ ance of the first annual index volume, covering the whole of the abstracts in pure and applied chemistry prepared and published under the direction of the Bureau of Chemical Abstracts during 1926, afforded us an opportunity of referring appreciatively to a scheme which has since proved a remarkably successful co-operative enterprise.

The Chemical Society, which since 1871 had undertaken the task of supplying abstracts of papers dealing with pure, physical, inorganic, organic, analytical, mineralogical and biological chemistry, and the Society of Chemical Industry, which had similarly surveyed applied chemistry since 1882, had for many years maintained mutually helpful contact between their respective abstracting organisations; in 1924, however, these two Societies united in establishing the Bureau of Chemical Abstracts, charging the new body with the task of controlling both the preparation and the publication of abstracts in all branches of pure and applied chemistry, and of securing such unification as might prove practicable. By the end of 1925 their efforts had been so far successful that consent had been secured to a common format for the two sections, known as British Chemical Abstracts $A$ and $B$, respectively, a considerable amount of overlapping material which had previously appeared in somewhat different forms in both sections was eliminated, and the publication of an annual index envisaging the whole range of pure and applied chemistry was undertaken. A few, of course, shook their heads disapprovingly 